Article

\title{
An Artificial Intelligence Method for Energy Efficient Operation of Crude Distillation Units under Uncertain Feed Composition
}

\author{
Muhammad Amin Durrani ${ }^{1}\left(\mathbb{D}\right.$, Iftikhar Ahmad ${ }^{1, * \mathbb{C}}$, Manabu Kano ${ }^{2} \mathbb{D}$ and Shinji Hasebe ${ }^{3}$ \\ 1 School of Chemical and Materials Engineering, National University of Sciences and Technology (NUST), \\ Sector H-12, Islamabad 44000, Pakistan; amin-che-ms01@scme.nust.edu.pk \\ 2 Department of Systems Science, Graduate School of Informatics, Kyoto University, Yoshida-Honmachi, \\ Sakyo-ku, Kyoto 606-8501, Japan; manabu@human.sys.i.kyoto-u.ac.jp \\ 3 Department of Chemical Engineering, Kyoto University, Nishikyo-ku, Kyoto 615-8510, Japan; \\ hasebe@cheme.kyoto-u.ac.jp \\ * Correspondence: iftikhar.salarzai@scme.nust.edu.pk; Tel.: +92-51-90855108
}

Received: 28 September 2018; Accepted: 29 October 2018; Published: 1 November 2018

check for updates

\begin{abstract}
The crude distillation unit (CDU) is one of the most energy-intensive processes of a petroleum refinery. The composition of crude is subject to change on regular basis. The uncertainty in crude oil composition causes wastage of a substantial amount of energy in the CDU operation. In this study, a novel approach based on a multi-output artificial neural networks (ANN) model was devised to cope with variations (uncertainty) in crude composition. The proposed method is an extended version of another method of cut-point optimization based on hybridization of Taguchi and genetic algorithm. A data comprised of several hundred variations of crude compositions and their optimized cut point temperatures, derived from the hybrid approach, was used to train the ANN model. The proposed method was validated on a simulated CDU flowsheet for a Pakistani crude, i.e., Zamzama. The proposed method is faster and computationally less expensive than the hybrid method. In addition, it can efficiently predict optimum cut point temperatures for any variant of the crude composition.
\end{abstract}

Keywords: crude distillation unit; energy efficiency; Taguchi method; genetic algorithm; artificial neural networks

\section{Introduction}

Petroleum refining is one of the largest energy consuming industrial sectors. Thus, it is always desired to realize an energy efficient process design and operation. According to a study conducted by the US Department of Energy, 794 TBTU/year (26\%) of energy could be saved if the current R\&D-based technologies were effectively implemented in US petroleum refineries [1]. The major opportunities for saving energy are in the crude distillation, hydrotreating, reforming, vacuum distillation, and catalytic cracking units. The crude distillation unit (CDU) has the highest energy saving potential among all other process units; Figure 1 shows the energy saving opportunities of process units across the refinery, where the atmospheric CDU, the subject of this study, surpasses all the other units.

Due to its immense importance, CDU has been the focus of research from various aspects, i.e., scheduling of crude [2-5], estimation of product properties [6-9], optimization and control of important parameters of CDU [10-13], and cut point temperature optimization [14-21]. CDU fractionates crude oil at the cut point temperatures of the respective products such as naphtha, kerosene, and diesel. The tray temperature at which the product streams are separated, called cut-point temperature, is crucial in 
realizing energy-efficient operation of a CDU. The cut point temperatures heavily depend on the crude composition and need to be optimized whenever a new crude blend is incorporated into the feed.

Several optimization methods have been developed for the cut point temperatures optimization. These methods include mode or categorization approach [14], fixed yield structure representations model [15], swing cut modeling [16], weight transfer ratio (WTR) approach [17], fractionation index model [18], Taguchi method [19], monotonic interpolation [20], and hybrid framework of Taguchi method and genetic algorithm (GA) [21].

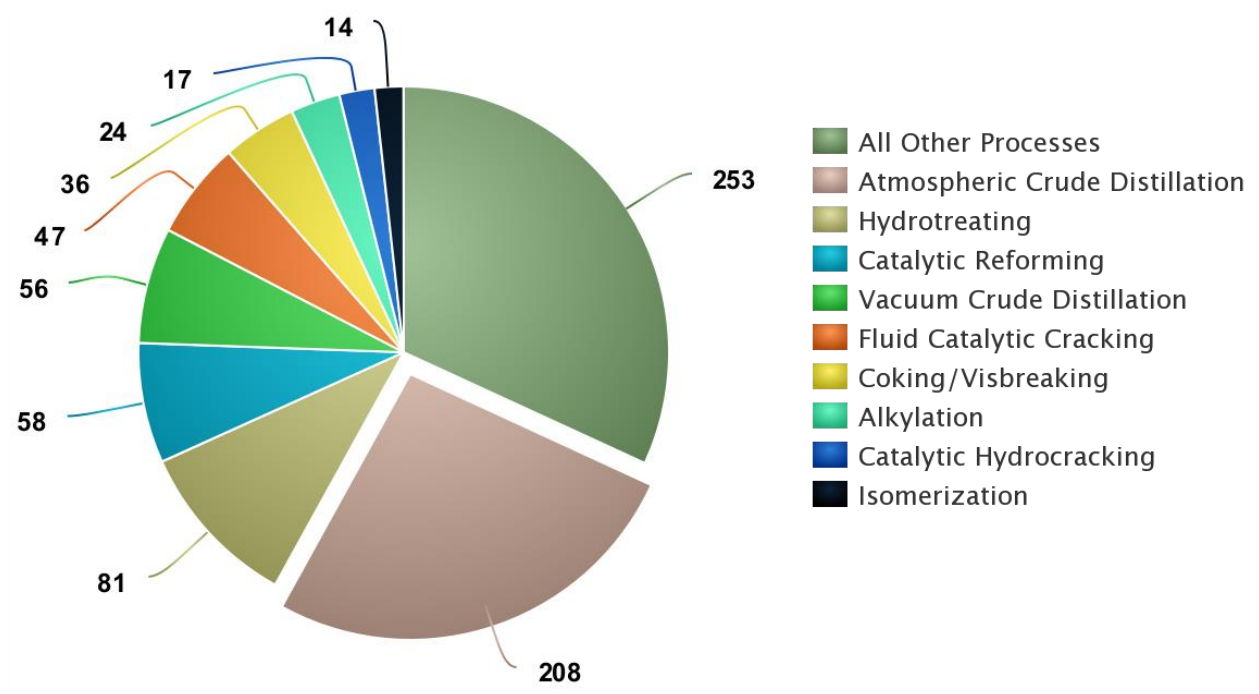

Figure 1. Potential of energy savings in petroleum refineries (energy savings per annum in trillion BTUs) [1].

Brooks et al. used a mode-based approach to realize an optimal plan for CDU operation [14]. Spreadsheets were used to blend CDU modes keeping in mind the specifications of the final products. Similarly, the fixed yield modeling uses linear equations for CDU yield prediction [15]. The equations are adopted on the basis of feed multiplied by a coefficient generated accordingly. The swing cut approach fine-tunes the fixed cut to further optimize the CDU model [16]. A small portion of the yield near the cut-point is allowed to adjust or "swing" to improve the objective function.

In the weight transfer ratio (WTR) approach, cut-point temperatures are determined on the basis of the weight transfer ratio (WTR) ranges of CDU fractions [17]. Initially, cut-points for operation modes are calculated using ASTM D86 boiling ranges. Then the range of maximum and minimum WTRs are utilized in the planning model to optimize the cut-points of the different CDU fractions. In the fractionation index (FI) model, representation of the complex CDU is split into a series of simple fractionation units modeled using a simple common equation of component distribution [18].

Ali et al. performed optimization of cut point temperatures of a CDU using a statistical approach known as the Taguchi method [19]. Straight run cut point temperatures of three Malaysian crude oils were taken as reference and a virtual CDU of $100 \mathrm{kBPD}$ was simulated in the Aspen HYSYS environment. The monotonic interpolation-based optimization of CDU allows the distillation curve to be manipulated using the cut points [20]. In our earlier study, a new cut point temperatures optimization technique was developed through hybridization of the Taguchi method and a genetic algorithm [21]. The hybrid approach comprised of two phases; the first phase used the Taguchi method to optimize the cut point temperatures while the genetic algorithm in the second phase performed further optimization.

The cut point optimization methods, in general, face a challenge in coping with the uncertainty in the feed composition of the CDU; for each variant of the feed composition, the computationally expensive optimization methods must be re-run to update the cut points. The uncertainty arises from the frequent scheduling process which depends on several uncertain parameters, i.e., availability of 
crude sources, prices, machine reliability, and market requirements [22-27]. Operation of a CDU under uncertain feed composition conditions causes wastage of a substantial amount of energy.

Intelligent systems have been the subject of high interest in order to cope with challenges and realize higher efficiency in energy management systems. Applications of intelligent systems have been reported in ventilating and air-conditioning systems, solar radiation systems, power-generation systems, energy load management and refrigeration system [28]. For instance, a relation between operating parameters and performance of a solar thermal energy system (STES) was investigated through an adaptive neuro-fuzzy inference system (ANFIS) [29]. In addition, the ANFIS was compared with artificial neural networks (ANNs) methods where both methods provided high accuracy and reliability. In another work, an intelligent method like ANN was integrated with genetic algorithms for optimization of a solar-energy system [30]. In a study on lead-acid batteries formation, an intelligent energy performance indicator (EnPI) was used to evaluate the process energy efficiency [31]. EnPI reduced the electricity consumption of battery manufacture from 3\% to $5 \%$. A comprehensive review on the role of artificial intelligence methods in renewable energy systems such as wind energy, geothermal energy, ocean energy, hydro energy, solar energy, hydrogen energy, bioenergy, and hybrid energy can be found in [32].

The current study is also based on the use of ANN in realizing energy efficient operation of CDU. The hybrid framework of the Taguchi method and genetic algorithm (GA) was integrated with a multi-output ANN model to cope with uncertainty in the crude composition. A dataset comprised of several hundred variations of crude compositions and their optimized cut point temperatures, derived from the hybrid approach, was used to train the ANN model. The proposed method was validated on a simulated CDU flowsheet for a Pakistani crude, i.e., Zamzama. The proposed method is faster and computationally less expensive than the hybrid method. In addition, it can efficiently predict optimum cut point temperatures for any variant of the crude composition.

The remainder of the paper is organized as follows: Section 2 presents the process description and the proposed methodology. Results and discussion are presented in Section 3 while Section 4 concludes the work.

\section{Process Description and Methodology}

\subsection{Process Description}

Figure 2 shows a process flow sheet of a CDU. The flowsheet was designed for compositions of three Pakistani crudes, i.e., Bobi, Kunnar, and Zamzama [21]. All three crudes were sweet and light, with specific gravities ranging between 0.75 and 0.76 , and a sulfur content of less than 0.05 weight percent and water content of less than 0.05 volume percent, as shown in Table 1. Seven feed blends were devised from the three crudes: three mono crude feeds, i.e., Bobi, Kunnar, and Zamzama, three binary crude blends, i.e., Bobi-Kunnar blend, Bobi-Zamzama blend, and Kunnar-Zamzama blend and one tertiary blend, i.e., Bobi-Kunnar-Zamzama blend. The crude assay was characterized and hypothetical components were generated in HYSYS Oil. Figure 3 shows the true boiling point (TBP) curves of three crudes, which were generated by using hypothetical components.

Crude oil at $232.222{ }^{\circ} \mathrm{C}$ temperature and $517.107 \mathrm{kPa}$ pressure was pumped to the pre-flash column at a rate of $100 \mathrm{kBPD}$. The pre-flash column separated the vapors from the liquid to reduce the duty on the furnace. The liquid crude from pre-flash column was pumped to the furnace in order to preheat the crude oil. The preheated crude oil was then pumped to the CDU column. The fractionation column had 29 theoretical trays and was connected with three pump arounds, three side strippers, and a three-phase partial condenser; summary of the specifications and CDU parameters is shown in Table 2.

Hot crude from the furnace and the pre-flash vapor from the pre-flash column were passed through the mixer and then introduced at the tray 28 of the column. Three side-strippers, each of which had tray sections, were used in the column. Parameters used in the side strippers are listed 
in Table 3. The top tray pressure of the column was $135.82 \mathrm{kPa}$ with a pressure drop of $62.05 \mathrm{kPa}$ while the bottom pressure was $225.45 \mathrm{kPa}$. Three pump-around were installed for internal reflux with parameters shown in Table 4.

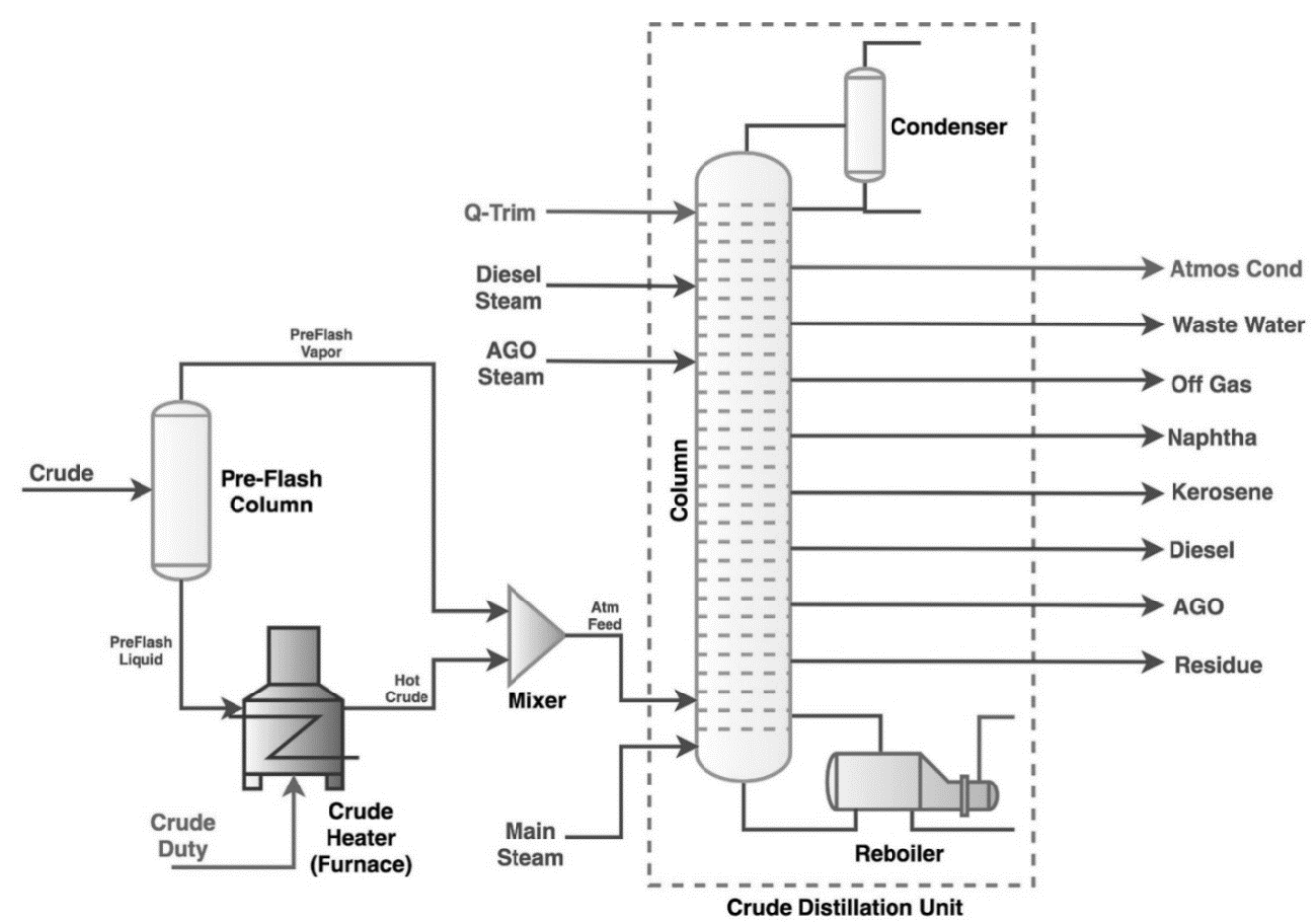

Figure 2. Crude distillation unit process flow diagram.

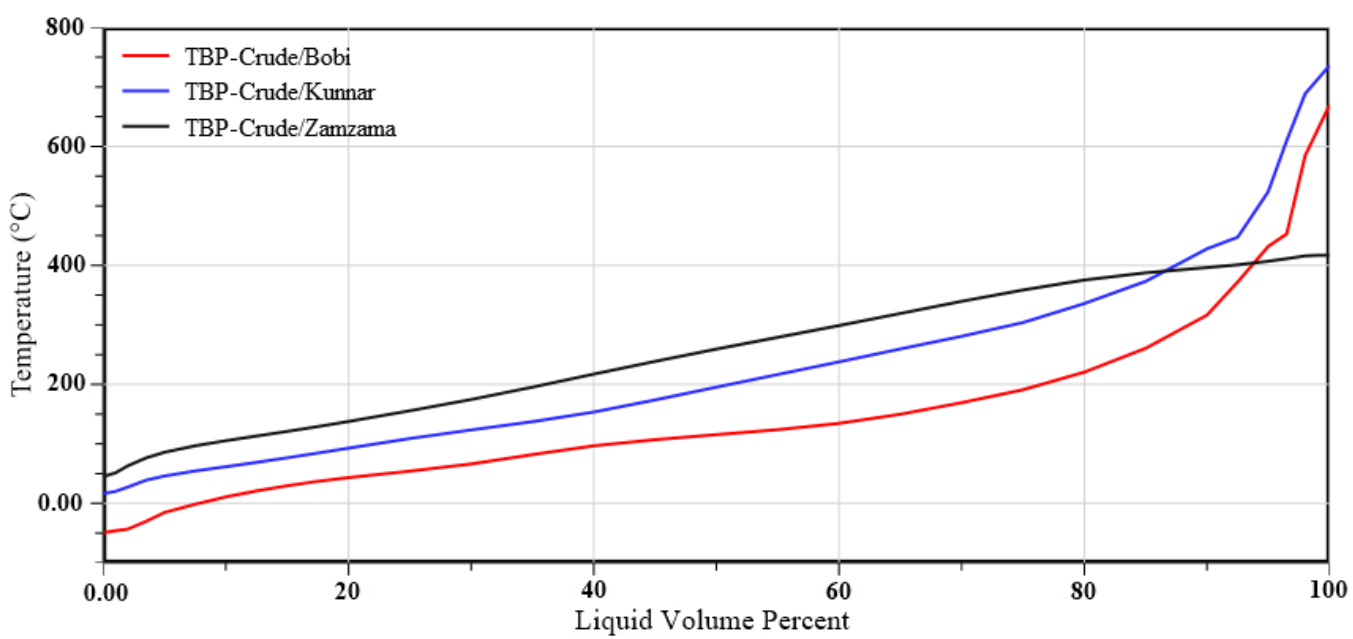

Figure 3. TBP Curves for the three Pakistani Crude Oils generated through Aspen HYSYS.

Table 1. Specifications of Pakistani Crudes: Bobi, Kunnar and Zamzama.

\begin{tabular}{cccc}
\hline Test Description & Bobi & Kunnar & Zamzama \\
\hline Specific Gravity 60/60 F & 0.7513 & 0.7934 & 0.7588 \\
Total Sulphur Content (Wt.\%) & 0.05 & 0.0376 & 0.0083 \\
Basic Sediment (Vol \%) & 0.05 & $<0.05$ & $<0.05$ \\
Water Content (Vol \%) & 0.02 & $<0.05$ & $<0.05$ \\
Salt Content Lb/1000 bbl & $<1$ & 4.5 & Nil \\
Kinematic Viscosity 40 C (cSt) & 0.8 & 1.27 & 0.78 \\
\hline
\end{tabular}


Table 2. Parameters for Designing the CDU [21].

\begin{tabular}{cc}
\hline Parameters & Values \\
\hline Total Number of Trays & 29 \\
Column Temperature & $70.99^{\circ} \mathrm{C}$ (top tray) \\
& $338.57^{\circ} \mathrm{C}$ (bottom tray) \\
Column Pressure & $135.82 \mathrm{kPa}$ (top tray) \\
Number of pump arounds & $225.45 \mathrm{kPa}$ (bottom tray) \\
Number of side strippers & 3 \\
Crude Feed Rate & 3 \\
Crude Feed Location & $100.00 \mathrm{kBPD}$ \\
Crude Feed Temperature & Tray-28 \\
Crude Feed Pressure & $328.60{ }^{\circ} \mathrm{C}$ \\
Type of Condenser & $448.20 \mathrm{kPa}$ \\
Fluid Package & Partial Condenser \\
\hline
\end{tabular}

Table 3. Specifications for Side-Strippers [21].

\begin{tabular}{ccccc}
\hline Side Strippers & Draw Line & Return Line & Stripping Through & Flow/Duty \\
\hline SS-1 & Tray-9 & Tray-8 & Reboiler & $2198.03 \mathrm{~kW}$ \\
SS-2 & Tray-17 & Tray-16 & Steam & $1362.00 \mathrm{~kg} / \mathrm{h}$ \\
SS-3 & Tray-22 & Tray-21 & Steam & $1135.00 \mathrm{~kg} / \mathrm{h}$ \\
\hline
\end{tabular}

Table 4. Specifications for Pump-Arounds [21].

\begin{tabular}{ccccc}
\hline Pump Arounds & Draw Line & Return Line & Duty (kW) & Flow (kBPD) \\
\hline PA-1 & Tray-2 & Tray-1 & $-16,118.91$ & 50.00 \\
PA-2 & Tray-17 & Tray-16 & $-10,257.48$ & 29.99 \\
PA-3 & Tray-22 & Tray-21 & $-10,257.48$ & 30.00 \\
\hline
\end{tabular}

\subsection{Modeling Method}

In the proposed method, the ANN model was integrated with the hybrid framework. The procedure is schematically shown in Figure 4 and the main steps are listed below:

Phase I: Several crude compositions/blends are generated through inserting variations/uncertainty in compositions of a Zamzama crude/assay.

Phase II: Cut-point temperatures of the composition/blends are calculated through the hybrid, i.e., Taguchi and GA, optimization framework. The hybrid framework involves the following steps:

(a) Specify the number of controlling factors and levels for the Taguchi method.

(b) Develop a standard orthogonal array for the specified factors and levels.

(c) Draw response plots and select cut point temperatures with minimum E/V values.

(d) Generate an initial population of the cut point temperatures for GA application.

(e) Specify the upper and the lower limits of the cut point temperature and fitness function.

(f) Derive E/V values against the generated cut point temperatures. If the fitness function and/or stopping criteria are satisfied, optimization is achieved otherwise the generation of population and fitness test procedure is repeated.

Phase III: The datasets comprising of the compositions and their corresponding cut points are used to develop the ANN model.

Phase IV: The ANN model is then used to predict cut point temperatures for any varied composition of the assay. 


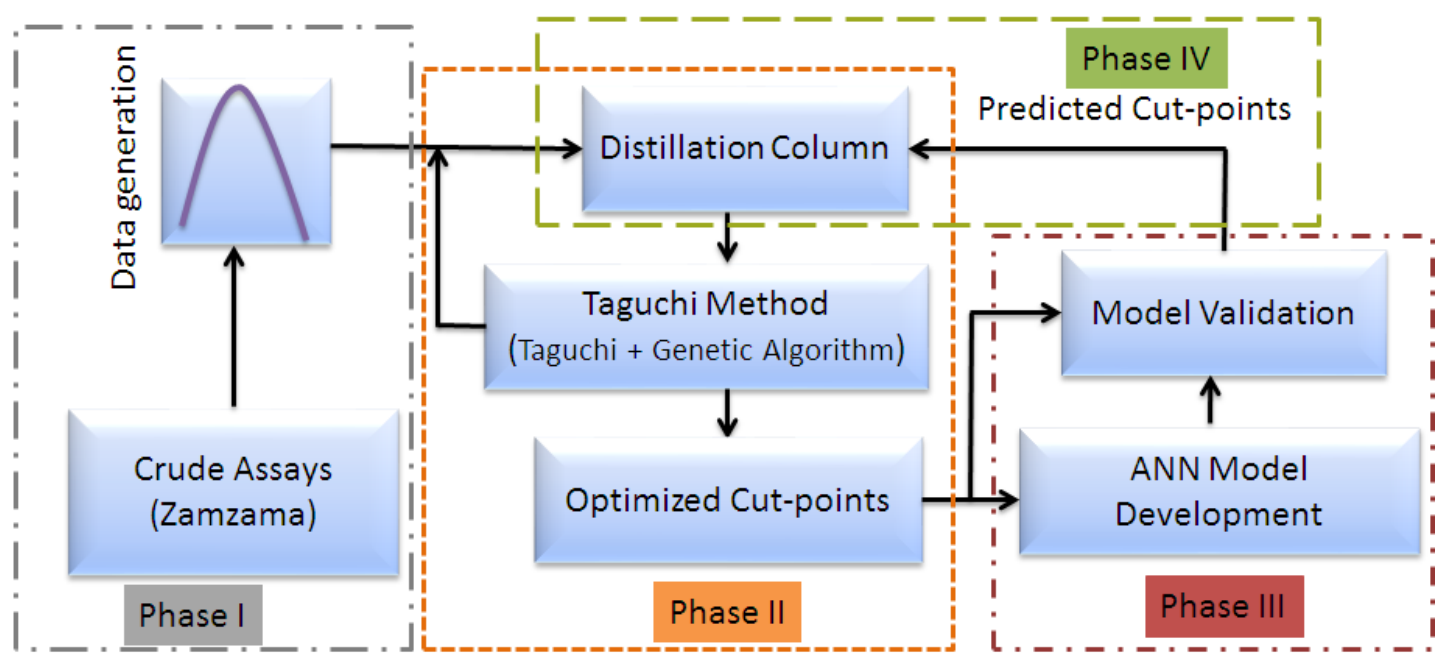

Figure 4. Schematic diagram of integration of hybrid framework and ANN model.

\section{Results and Discussion}

The results are discussed in two phases; initially, observations of the hybrid framework are described in Section 3.1 followed by results of the ANN model in Section 3.2. The overall findings are discussed in Section 3.3.

\subsection{Results of Hybrid Optimization Framework}

For the hybrid framework, initially, four controlling factors were devised. Three levels of the cut point temperatures were chosen at $\pm 5^{\circ} \mathrm{C}$ of the straight run cut point temperatures as shown in Table 5. For the 4-factors and 3-levels, a standard L9 orthogonal array was determined.

Table 5. Factors and levels for the optimization of CDU [21].

\begin{tabular}{ccccc}
\hline & Factors & Level A & Level B & Level C \\
\hline 1 & Cutpoint Temperature (Naphtha) & $-5{ }^{\circ} \mathrm{C}$ & SR Temp & $+5{ }^{\circ} \mathrm{C}$ \\
2 & Cutpoint Temperature (Kerosene) & $-5^{\circ} \mathrm{C}$ & SR Temp & $+5{ }^{\circ} \mathrm{C}$ \\
3 & Cutpoint Temperature (Diesel) & $-5^{\circ} \mathrm{C}$ & SR Temp & $+5{ }^{\circ} \mathrm{C}$ \\
4 & Cutpoint Temperature (AGO) & $-5{ }^{\circ} \mathrm{C}$ & SR Temp & $+5{ }^{\circ} \mathrm{C}$ \\
\hline
\end{tabular}

Trial runs were performed for each factor in the Aspen HYSYS simulation by putting the cut point temperatures assigned by the levels. Recipes for the optimized cut points for Zamzama crude along with six other cases is listed in Table 6.

Table 6. Recipe for optimized cut points of seven crude blends [21].

\begin{tabular}{ccccc}
\hline & \multicolumn{4}{c}{ Factors } \\
\cline { 2 - 5 } Crude Blends & $\mathbf{1}$ & $\mathbf{2}$ & $\mathbf{3}$ & $\mathbf{4}$ \\
& (Naphtha) & (Kerosene) & (Diesel) & (AGO) \\
\hline Blend A: Bobi Oil & $\mathrm{B}$ & $\mathrm{A}$ & $\mathrm{B}$ & $\mathrm{A}$ \\
Blend B: Kunnar & $\mathrm{B}$ & $\mathrm{A}$ & $\mathrm{C}$ & $\mathrm{A}$ \\
Blend C: Zamzama & $\mathrm{C}$ & $\mathrm{A}$ & $\mathrm{C}$ & $\mathrm{A}$ \\
Blend D: Bobi + Kunnar Blend & $\mathrm{C}$ & $\mathrm{A}$ & $\mathrm{C}$ & $\mathrm{A}$ \\
Blend E: Bobi + Zamzama Blend & $\mathrm{A}$ & $\mathrm{A}$ & $\mathrm{C}$ & $\mathrm{A}$ \\
Blend F: Kunnar + Zamzama Blend & $\mathrm{A}$ & $\mathrm{A}$ & $\mathrm{C}$ & $\mathrm{A}$ \\
Blend G: Bobi + Kunnar + Zamzama Blend & $\mathrm{B}$ & $\mathrm{A}$ & $\mathrm{C}$ & $\mathrm{C}$ \\
\hline
\end{tabular}

E/V values were calculated by running the optimized cut point temperatures in the Aspen HYSYS model simulation, shown in Table 7. To achieve further optimization, GA was applied to the Taguchi 
optimized cut point temperatures. Upper and lower bound of $\pm 2.5^{\circ} \mathrm{C}$ of cut point temperatures, the population of 100 samples, iterations of 10 generations and tolerance function of $1 \times 10^{-4}$ were used. The comparison between the straight run, Taguchi method and hybrid optimization framework for blend $\mathrm{C}$ is shown in Table 7.

Table 7. Result comparison of straight run, Taguchi method, and hybrid framework for blend C (Zamzama Crude) [21].

\begin{tabular}{cccc}
\hline Method & Objective Functions & Unit & Blend C (Zamzama) \\
\hline \multirow{2}{*}{ Straight Run Results } & $\mathrm{E} / \mathrm{V}$ & $\mathrm{kW} / \mathrm{kBPD}$ & 1104.12 \\
& Diesel Output & $\mathrm{kBPD}$ & 37.52 \\
\hline \multirow{2}{*}{ Taguchi Optimized Results } & $\mathrm{E} / \mathrm{V}$ & $\mathrm{kW} / \mathrm{kBPD}$ & 979.30 \\
& Diesel Output & $\mathrm{kBPD}$ & 40.09 \\
\hline \multirow{2}{*}{ Hybrid Framework Results } & $\mathrm{E} / \mathrm{V}$ & $\mathrm{kW} / \mathrm{kBPD}$ & 895.41 \\
& Diesel Output & $\mathrm{kBPD}$ & 41.59 \\
\hline
\end{tabular}

\subsection{Results of Data-Driven Approach Based on ANN}

For the development of the ANN-based model, 33 components of Zamzama crude were used as inputs while the four cut points, i.e., naphtha, kerosene, diesel, and AGO, were used as output. 192 feed compositions of Zamzama crude were developed. The original value of each component of the assay was altered for $-3 \%,-2 \%,-1 \%, 1 \%, 2 \%$ and $3 \%$ and the other components of the essay were also adjusted, accordingly.

Six sample variants (datasets) of the original blend, i.e., blend C, are shown in Table 8. A total of 192 data sets were generated. $164(85 \%)$ datasets were used to develop the multi-output ANN model while $28(15 \%)$ were used for validation. The ANN model had three hidden layers where a number of neurons in hidden layers 1, 2 and 3 were 13,17, and 16, respectively. The correlation coefficient between the targets cut point and the predicted cut points was 0.99 as shown in Figure 5.

Table 8. Six sample variants of Zamzama crude.

\begin{tabular}{ccccccc}
\hline Component No. & Dataset 1 & Dataset 2 & Dataset 3 & Dataset 4 & Dataset 5 & Dataset 6 \\
\hline 1 & 0.023626351 & 0.023665842 & 0.0236852 & 0.023666 & 0.0236273 & 0.02356837 \\
2 & 0.027626334 & 0.027672511 & 0.0276952 & 0.0276727 & 0.0276275 & 0.02755854 \\
3 & 0.036053581 & 0.036113844 & 0.0361434 & 0.0361141 & 0.0360551 & 0.0359651 \\
4 & 0.061877081 & 0.061980508 & 0.0620313 & 0.061981 & 0.0618797 & 0.06172523 \\
5 & 0.082073145 & 0.082210329 & 0.0822777 & 0.082211 & 0.0820766 & 0.08187173 \\
6 & 0.08343473 & 0.081902706 & 0.0811501 & 0.0818952 & 0.0833965 & 0.08568402 \\
7 & 0.091063729 & 0.091215941 & 0.0912907 & 0.0912167 & 0.0910675 & 0.09084026 \\
8 & 0.071834448 & 0.071954518 & 0.0720135 & 0.0719551 & 0.0718374 & 0.07165816 \\
9 & 0.056970183 & 0.057065407 & 0.0571122 & 0.0570659 & 0.0569726 & 0.05683038 \\
10 & 0.052350227 & 0.05243773 & 0.0524807 & 0.0524382 & 0.0523524 & 0.05222176 \\
11 & 0.047732605 & 0.047812389 & 0.0478516 & 0.0478128 & 0.0477346 & 0.04761547 \\
12 & 0.041477561 & 0.04154689 & 0.0415809 & 0.0415472 & 0.0414793 & 0.04137577 \\
13 & 0.035915059 & 0.035975091 & 0.0360046 & 0.0359754 & 0.0359166 & 0.03582692 \\
14 & 0.032084289 & 0.032137918 & 0.0321643 & 0.0321382 & 0.0320856 & 0.03200555 \\
15 & 0.028328743 & 0.028376094 & 0.0283994 & 0.0283763 & 0.0283299 & 0.02825922 \\
16 & 0.025733674 & 0.025776688 & 0.0257978 & 0.0257769 & 0.0257347 & 0.02567052 \\
17 & 0.024027203 & 0.024067365 & 0.0240871 & 0.0240676 & 0.0240282 & 0.02396824 \\
18 & 0.024935002 & 0.024976681 & 0.0249972 & 0.0249769 & 0.024936 & 0.02487381 \\
19 & 0.024652781 & 0.024693987 & 0.0247142 & 0.0246942 & 0.0246538 & 0.02459228 \\
20 & 0.021172035 & 0.021207423 & 0.0212248 & 0.0212076 & 0.0211729 & 0.02112008 \\
21 & 0.017883244 & 0.017913135 & 0.0179278 & 0.0179133 & 0.017884 & 0.01783936 \\
22 & 0.01491413 & 0.014939059 & 0.0149513 & 0.0149392 & 0.0149148 & 0.01487753 \\
23 & 0.012335549 & 0.012356168 & 0.0123663 & 0.0123563 & 0.0123361 & 0.01230528 \\
24 & 0.010290474 & 0.010307675 & 0.0103161 & 0.0103078 & 0.0102909 & 0.01026522 \\
25 & 0.008847667 & 0.008862455 & 0.0088697 & 0.0088625 & 0.008848 & 0.00882595 \\
\hline
\end{tabular}


Table 8. Cont.

\begin{tabular}{ccccccc}
\hline Component No. & Dataset 1 & Dataset 2 & Dataset 3 & Dataset 4 & Dataset 5 & Dataset 6 \\
\hline 26 & 0.007717981 & 0.007730881 & 0.0077372 & 0.0077309 & 0.0077183 & 0.00769904 \\
27 & 0.006733757 & 0.006745012 & 0.0067505 & 0.0067451 & 0.006734 & 0.00671723 \\
28 & 0.005805959 & 0.005815663 & 0.0058204 & 0.0058157 & 0.0058062 & 0.00579171 \\
29 & 0.005260808 & 0.005269601 & 0.0052739 & 0.0052696 & 0.005261 & 0.0052479 \\
30 & 0.004453308 & 0.004460752 & 0.0044644 & 0.0044608 & 0.0044535 & 0.00444238 \\
31 & 0.00623265 & 0.006243067 & 0.0062482 & 0.0062431 & 0.0062329 & 0.00621735 \\
32 & 0.003340658 & 0.003346242 & 0.003349 & 0.0033463 & 0.0033408 & 0.00333246 \\
33 & 0.003215055 & 0.003220429 & 0.0032231 & 0.0032205 & 0.0032152 & 0.00320716 \\
\hline
\end{tabular}

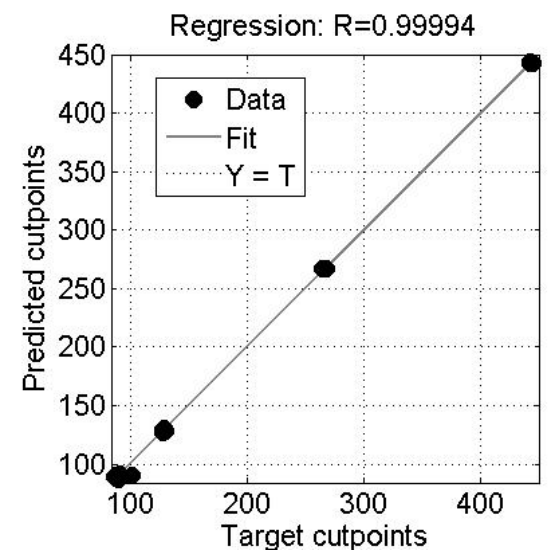

Figure 5. ANN-based prediction of cut points.

\subsection{Discussion}

In the Taguchi method, a decrease of energy requirement from $10.99 \%$ to $44.56 \%$ for the production of a kilo barrel of diesel was achieved compared to the straight run approach (SR). In the case of a hybrid framework, a decrease in energy requirement from $15.66 \%$ to $55.14 \%$ was observed when compared to the straight run approach (SR). Similarly, in the Taguchi method, an increase of $6.84 \%$ to $32.56 \%$ in the diesel production was observed, while in case of a hybrid framework, an increase of $11.33 \%$ to $35.54 \%$ in diesel production was achieved. The hybrid framework clearly outperforms the straight run and Taguchi-based methods both in energy consumption minimization and increase in diesel production. However, the hybrid approach has also a limitation; it needs too much time for iterations to update cut-points whenever a variation in the assay composition occurs. Considering the fact that feed composition of CDU is prone to changes due to an abrupt shortage in feedstock or change in product demand, the hybrid approach becomes less feasible.

The ANN method aimed at reducing the time needed for updating cut points in response to variation in crude composition. The cut points predicted by the ANN model were fed to the distillation columns and their respective E/V and diesel production values were obtained. E/V values for the ANN model, straight run (SR) approach, Taguchi method, and hybrid framework are shown in Figure 6. Average E/V values for the twenty-eight testing variants (datasets) of Figure 6 are shown in Figure 7. Average E/V values obtained through the ANN approach are comparable (rather slight lower/better) than the hybrid approach and way better than the Taguchi and straight run (SR) approach.

Similarly, the amount of diesel produced using the cut-points obtained through the ANN model, straight run (SR) approach, Taguchi method, and hybrid framework are shown in Figure 8. Average diesel production values for the twenty-eight testing variants (datasets) of Figure 8 are shown in Figure 9. Diesel production obtained through the ANN based approach are comparable (rather slight higher/better) than the hybrid approach and way better than the Taguchi and straight run (SR) approach. 


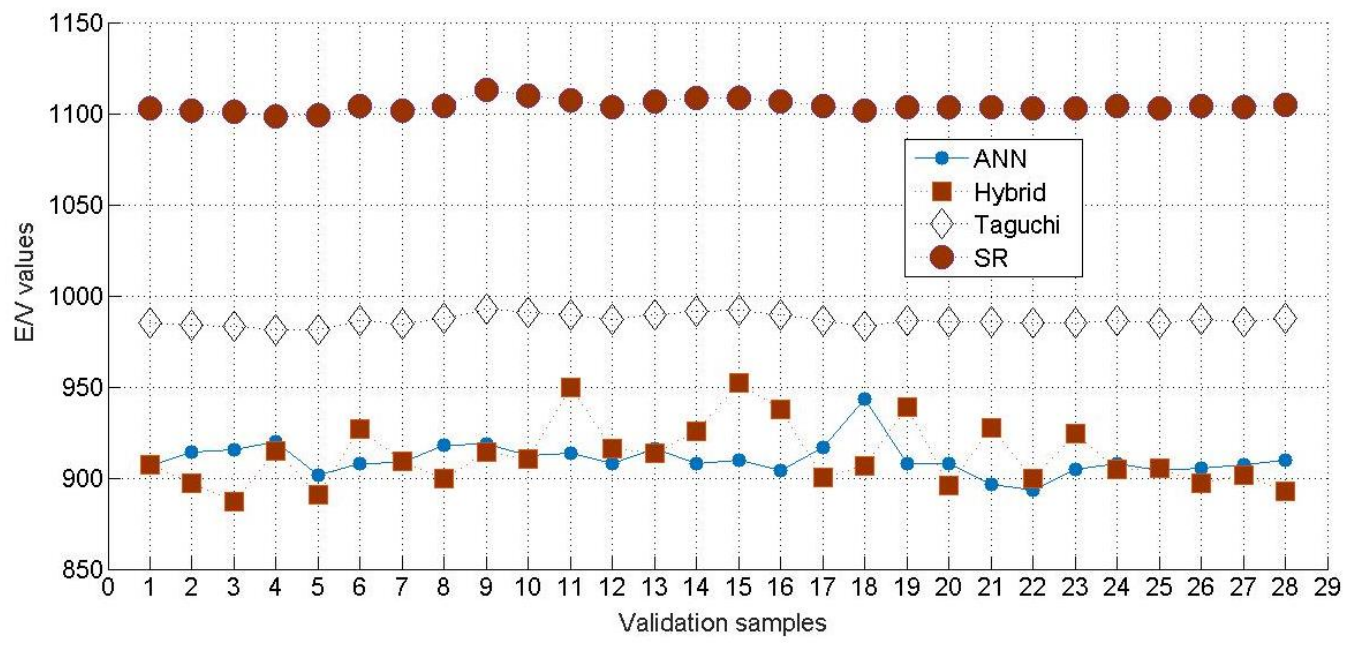

Figure 6. Comparison of E/V values obtained through straight run (SR), Taguchi technique, hybrid framework, and ANN model.

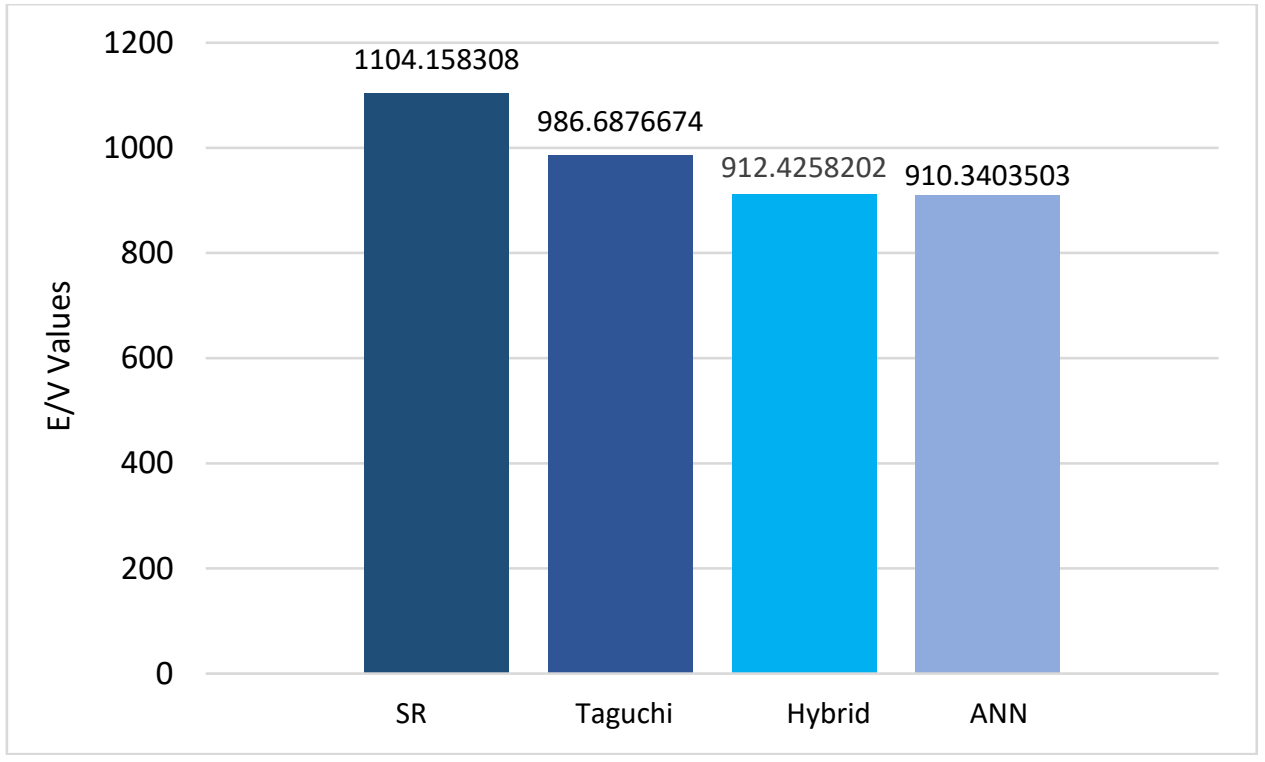

Figure 7. Average energy consumption for 28 testing variants (datasets) of Zamzam crude.

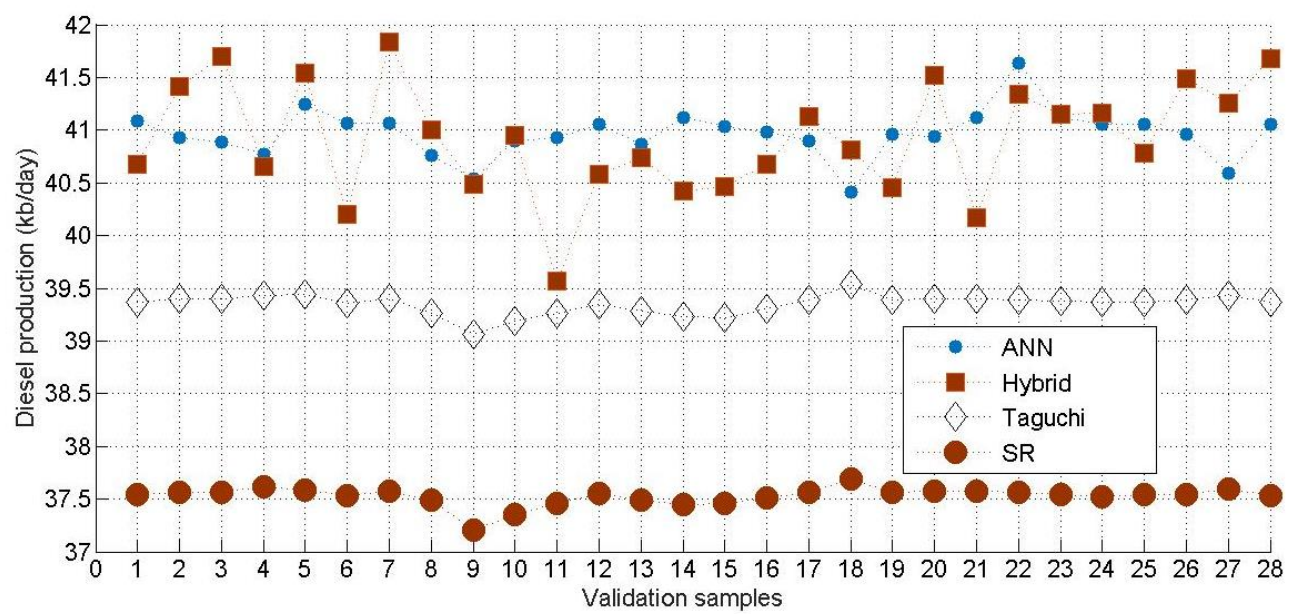

Figure 8. Comparison of diesel production obtained through straight run (SR), Taguchi technique, hybrid framework, and ANN model. 


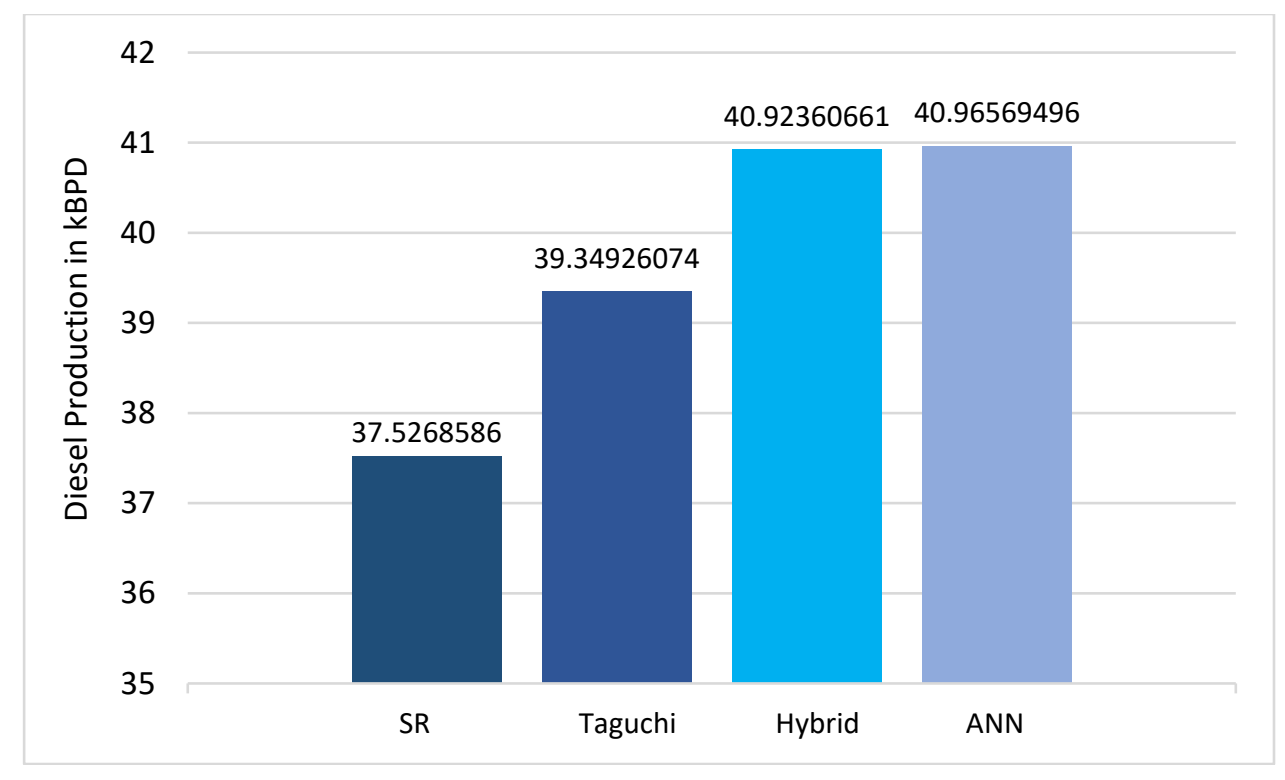

Figure 9. Average diesel production of 28 testing samples.

Hence, it is evident that the proposed data-driven approach is highly efficient in predicting the optimum cut-points without going through the time consuming iterative steps of optimization. The ANN model once trained on a given crude blend can handle variants of the crude in running process of CDU operation. The proposed approach will not only reduce the time required for tuning of CDU but will save substantial amount of energy lost during the conventional method of updating the cut-point temperature.

\section{Conclusions}

In this study, a conventional hybrid framework of Taguchi method and genetic algorithm (GA) for cut point temperature optimization was integrated with a data-driven method to make it robust to uncertainty in the crude composition. A multi-output artificial neural networks (ANN) model was adopted as a data-driven method. Artificial variations were inserted in the standard composition of Zamzama crude from Pakistan to produce 192 variants (data-sets). The hybrid framework of Taguchi method and genetic algorithm (GA) was used to determine optimum cut-point temperatures of the variants. The variants and their corresponding cut-points were used to develop an ANN model. The ANN model drastically reduced the calculation time and was capable of predicting optimum cut-points for testing variants of Zamzama crude with a high accuracy. The proposed approach will not only reduce the time required for tuning of CDUs, but will save a substantial amount of the energy lost during the conventional method of updating the cut-point temperature.

In future work, the proposed method can be extended to other types of crudes, i.e., single crudes or blends of several crudes. Furthermore, uncertainty in process condition, i.e., temperature, pressure, etc., can also be added to the presently considered uncertainty in crude composition. In that context, use of some uncertainty quantification methods such a polynomial chaos expansion (PCE) or Monte Carlo's (MC) are recommended.

Author Contributions: Conceptualization, I.A.; Formal analysis, M.A.D.; Methodology, M.A.D.; Supervision, I.A.; Writing-review \& editing, M.K. and S.H.

Funding: This research received no external funding.

Conflicts of Interest: The authors declare no conflicts of interest. 


\section{Nomenclature}

$\begin{array}{ll}\text { AGO } & \text { Atmospheric Gas Oil } \\ \text { ANN } & \text { Artificial Neural Network } \\ \text { ASTM } & \text { American Society for Testing and Materials } \\ \text { BPD } & \text { Barrels Per Day } \\ \text { BTU } & \text { British Thermal Unit } \\ \text { CDU } & \text { Crude Distillation Unit } \\ \text { DOE } & \text { Design of Experiments } \\ \text { E } & \text { Energy } \\ \text { EFV } & \text { Equilibrium Flash Evaporation } \\ \text { GA } & \text { Genetic Algorithm } \\ \text { MC } & \text { Monte Carlo's Method } \\ \text { PA } & \text { Pump Around } \\ \text { PCE } & \text { Polynomial Chaos Expansion } \\ \text { SRT } & \text { Straight Run Temperature } \\ \text { SS } & \text { Side Stripper } \\ \text { TBP } & \text { True Boiling Point } \\ \text { V } & \text { Volumetric Flow Rate }\end{array}$

\section{References}

1. Brueske, S.; Kramer, C.; Fisher, A. Bandwidth Study on Energy Use and Potential Energy Saving Opportunities in U.S. Petroleum Refining; Energy Efficiency and Renewable Energy (EERE): Washington, DC, USA, 2015.

2. Saharidis, G.K.; Minoux, M.; Dallery, Y. Scheduling of Loading and Unloading of Crude Oil in a Refinery Using Event-Based Discrete Time Formulation. Comput. Chem. Eng. 2009, 33, 1413-1426. [CrossRef]

3. Chryssolouris, G.; Papakostas, N.; Mourtzis, D. Refinery Short-Term Scheduling with Tank Farm, Inventory and Distillation Management: An Integrated Simulation-Based Approach. Eur. J. Oper. Res. 2005, 166, 812-827. [CrossRef]

4. Qu, H.; Xu, J.; Wang, S.; Xu, Q. A Novel Minlp Model of Front-End Crude Scheduling for Refinery with Consideration of Inherent Upset Minimization. Comput. Chem. Eng. 2018, 117, 42-62. [CrossRef]

5. Qu, H.; Xu, J.; Wang, S.; Xu, Q. Optimal Front-End Crude Schedule for Refineries under Consideration of Inherent Upset Reduction. In Computer Aided Chemical Engineering; Elsevier: San Diego, CA, USA, 2018; pp. 1315-1320.

6. Rogina, A.; Šiško, I.; Mohler, I.; Ujević, Ž.; Bolf, N. Soft Sensor for Continuous Product Quality Estimation (in Crude Distillation Unit). Chem. Eng. Res. Des. 2011, 89, 2070-2077. [CrossRef]

7. Chatterjee, T.; Saraf, D.N. On-Line Estimation of Product Properties for Crude Distillation Units. J. Process Control 2004, 14, 61-77. [CrossRef]

8. Dam, M.; Saraf, D.N. Design of Neural Networks Using Genetic Algorithm for on-Line Property Estimation of Crude Fractionator Products. Comput. Chem. Eng. 2006, 30, 722-729. [CrossRef]

9. Torgashov, A.; Goncharov, A.; Zhuravlev, E. Evaluation of Steady-State and Dynamic Soft Sensors for Industrial Crude Distillation Unit under Parametric Constraints. IFAC-PapersOnLine 2018, 51, 566-571. [CrossRef]

10. Bolf, N.; Ivandic, M.; Galinec, G. Soft Sensors for Crude Distillation Unit Product Properties Estimation and Control. In Proceedings of the 2008 16th Mediterranean Conference on Control and Automation, Ajaccio, France, 25-27 June 2008.

11. Pannocchia, G.; Gallinelli, L.; Brambilla, A.; Marchetti, G.; Trivella, F. Rigorous Simulation and Model Predictive Control of a Crude Distillation Unit. IFAC Proc. 2006, 39, 635-640. [CrossRef]

12. Skogestad, S. Dynamics and Control of Distillation Columns-A Critical Survey. In Dynamics and Control of Chemical Reactors, Distillation Columns and Batch Processes; Elsevier: Maryland, MD, USA, 1992; pp. 11-35.

13. Luyben, W.L. Distillation Design and Control Using Aspen Simulation; John Wiley \& Sons: Jersey City, NJ, USA, 2013.

14. Brooks, R.W.; Van Walsem, F.D.; Drury, J. Choosing Cut-Points to Optimize Product Yields. Hydrocarbon Process. 1999, 78, 53-60. 
15. Trierwiler, D.; Tan, R.L. Advances in Crude Oil LP Modelling; National Petrochemical \& Refiners Association: Singapore, 2001; pp. 52-58.

16. Zhang, J.; Zhu, X.X.; Towler, G.P. A Level-by-Level Debottlenecking Approach in Refinery Operation. Ind. Eng. Chem. Res. 2001, 40, 1528-1540. [CrossRef]

17. Li, W.; Hui, C.W.; Karimi, I.A.; Srinivasan, R. A Novel CDU Model for Refinery Planning. Asia-Pac. J. Chem. Eng. 2007, 2, 282-293. [CrossRef]

18. Alattas, A.M.; Grossmann, I.E.; Palou-Rivera, I. Integration of Nonlinear Crude Distillation Unit Models in Refinery Planning Optimization. Ind. Eng. Chem. Res. 2011, 50, 6860-6870. [CrossRef]

19. Ali, S.F.; Yusoff, N. Determination of Optimal Cut Point Temperatures at Crude Distillation Unit Using the Taguchi Method. Int. J. Eng. Technol. 2012, 12, 36-46.

20. Kelly, J.D.; Menezes, B.C.; Grossmann, I.E. Distillation Blending and Cutpoint Temperature Optimization Using Monotonic Interpolation. Ind. Eng. Chem. Res. 2014, 53, 15146-15156. [CrossRef]

21. Durrani, M.A.; Avila, A.; Rafael, J.; Ahmad, I. An Integrated Mechanism of Genetic Algorithm and Taguchi Method for Cut-Point Temperatures Optimization of Crude Distillation Unit. In Proceedings of the 2018 International Conference on Computing, Mathematics and Engineering Technologies (iCoMET), Sukkur, Pakistan, 3-4 March 2018.

22. Janak, S.L.; Lin, X.; Floudas, C.A. A New Robust Optimization Approach for Scheduling under Uncertainty-II. Uncertainty with Known Probability Distribution. Comput. Chem. Eng. 2007, 31, 171-195. [CrossRef]

23. Li, Z.; Ierapetritou, M. Process Scheduling under Uncertainty: Review and Challenges. Comput. Chem. Eng. 2008, 32, 715-727. [CrossRef]

24. Lin, X.; Janak, S.L.; Floudas, C.A. A New Robust Optimization Approach for Scheduling under Uncertainty: I. Bounded Uncertainty. Comput. Chem. Eng. 2004, 28, 1069-1085. [CrossRef]

25. Sahinidis, N.V. Optimization under Uncertainty: State-of-the-Art and Opportunities. Comput. Chem. Eng. 2004, 28, 971-983. [CrossRef]

26. Ahmad, I.; Kano, M.; Hasebe, S. Dimensions and Analysis of Uncertainty in Industrial Modeling Process. J. Chem. Eng. Jpn. 2018, 51, 533-543. [CrossRef]

27. Panda, D.; Ramteke, M. Reactive Scheduling of Crude Oil Using Structure Adapted Genetic Algorithm under Multiple Uncertainties. Comput. Chem. Eng. 2018, 116, 333-351. [CrossRef]

28. Kalogirou, S.A. Artificial Neural Networks in Renewable Energy Systems Applications: A Review. Renew. Sustain. Energy Rev. 2001, 5, 373-401. [CrossRef]

29. Yaïci, W.; Entchev, E. Adaptive Neuro-Fuzzy Inference System Modelling for Performance Prediction of Solar Thermal Energy System. Renew. Energy 2016, 86, 302-315. [CrossRef]

30. Kalogirou, S.A. Optimization of Solar Systems Using Artificial Neural-Networks and Genetic Algorithms. Appl. Energy 2004, 77, 383-405. [CrossRef]

31. Cabello, J.J.; Sagastume, A.; Sousa, V.; Herrera, H.; Balbis, M.; Silva, J. Soft Sensors to Assess the Energy Consumption in the Formation of Lead-Acid Batteries. In Proceedings of the 6th International Workshop on Advances in Cleaner Production, São Paulo, Brazil, 24-26 May 2017.

32. Jha, S.K.; Bilalovic, J.; Jha, A.; Patel, N.; Zhang, H. Renewable Energy: Present Research and Future Scope of Artificial Intelligence. Renew. Sustain. Energy Rev. 2017, 77, 297-317. [CrossRef]

(C) 2018 by the authors. Licensee MDPI, Basel, Switzerland. This article is an open access article distributed under the terms and conditions of the Creative Commons Attribution (CC BY) license (http://creativecommons.org/licenses/by/4.0/). 